03

\title{
Влияние шероховатой поверхности на аэродинамические характеристики двухлопастного ветродвигателя с цилиндрическими лопастями
}

\author{
(C) Н.К. Танашева, ${ }^{1,3}$ Т.О. Кунакбаев, ${ }^{2}$ А.Н. Дюсембаева, ${ }^{1}$ Н.Н. Шуюшбаева, ${ }^{3}$ С.К. Дамекова ${ }^{3}$ \\ ${ }^{1}$ Карагандинский государственный университет им. акад. Е.А. Букетова, \\ 100028 Караганда, Казахстан \\ ${ }^{2}$ Казахский национальный университет им. аль-Фараби, \\ 050002 Алматы, Казахстан \\ ${ }^{3}$ Кокшетауский государственный университет им. Ш. Уалиханова, \\ 020000 Кокшетау, Казахстан \\ e-mail: nazgulya_tans@mail.ru
}

(Поступило в Редакцию 20 октября 2016 г.)

\begin{abstract}
Приведены результаты экспериментальных исследований по определению коэффициента лобового сопротивления и коэффициента силы тяги двухлопастного ветродвигателя на основе эффекта Магнуса с шероховатыми вращающимися цилиндрами в диапазоне скоростей воздушного потока 4-10 m/s $(\operatorname{Re}=26800-90000)$ при постоянном числе вращения цилиндрической лопасти вокруг собственной оси. Результаты показали, что увеличение числа Рейнольдса приводит к уменьшению коэффициента лобового сопротивления и коэффициента силы тяги. Экспериментально установлена степень влияния относительной шероховатости на аэродинамические характеристики двухлопастного ветродвигателя.
\end{abstract}

DOI: 10.21883/JTF.2017.11.45120.2073

\section{Введение}

Интерес к альтернативным источникам энергии в мире в последнее время стал особенно актуален. Для экономии топливно-энергетических ресурсов, снижения негативного влияния на окружающую среду, а также обеспечения электроэнергией регионов требуется развитие возобновляемых источников энергии. Одним из наиболее развивающихся типов возобновляемых источников энергии в мире выступает ветроэнергетика.

В Концепции перехода Республики Казахстан к устойчивому развитию на 2007-2024 гг. предполагается, что доля альтернативных источников энергии должна составить 5\% в общем энергетическом балансе страны к 2024 г. [1].

Таким образом, ветроэнергетика не только рассматривается как экологически „чистый“ источник энергии, но также поддерживает социально-экономическое развитие страны, ее энергетическую безопасность и снижает зависимость электроэнергии от цен на топливо.

Эффективное использование ветродвигателей наиболее привлекательно, так как не нарушается природный баланс энергии на планете и одновременно используется безотходная, экологически чистая технология производства энергии. Особый интерес представляет ветродвигатель на основе вращающихся цилиндров, который может эффективно работать даже при низких значениях скорости ветра. Для повышения эффективности работы такого ветродвигателя необходимо изучение способов оптимизации аэродинамических характеристик его элементов - системы вращающихся цилиндров переменного сечения. Следовательно, данная задача является актуальной как в научном плане, так и с точки зрения практического использования.

В работах [2,3] приведены результаты испытаний модели ветроэнергетической установки с эффектом Магнуса, т.е. с вращающимися цилиндрами вместо традиционных лопастей, а также аэродинамических параметров отдельно взятых цилиндров. В работах [4,5] исследованы аэродинамические характеристики обтекания двухлопастного ветродвигателя в турбулентном потоке с цилиндрическими роторами с гладкой поверхностью.

В работах [6,7] подробно рассмотрены аэродинамические силы вращающегося одиночного цилиндра с шероховатой и пористой поверхностью в потоке воздуха.

На основании проведенного анализа существующих исследований поставлена задача об экспериментальном исследовании влияния шероховатой поверхности цилиндрических лопастей на аэродинамические характеристики двухлопастного ветродвигателя на основе эффекта Магнуса.

Использование эффекта Магнуса при вращении цилиндра в потоке известно давно, однако возможность его практического использования в качестве движущей силы ветродвигателей нового поколения для малых скоростей потока систематизировано изучается только в последние годы.

Цель работы - изучение влияния шероховатой поверхности на аэродинамические характеристики двухлопастного ветродвигателя с цилиндрическими лопастями, работающего на малых скоростях ветра с использованием эффекта Магнуса. 


\section{Методика эксперимента}

В научной лаборатории аэродинамических измерений кафедры инженерной теплофизики имени профессора Ж.С. Акылбаева собрана опытная модель двухлопастного ветродвигателя, работающего на основе эффекта Магнуса, который в последующем исследовался в поперечном потоке воздуха с различной скоростью ветра. Макет установливается в рабочей части аэродинамической трубы Т-1-М, прикрепленной с помощью тонких металлических растяжек к раме трехкомпонентных аэродинамических весов. Трехкомпонентные аэродинамические весы с достаточно высокой степенью точности позволяют измерять силу лобового сопротивления. Для измерения силы тяги основного вала ветродвигателя применялся пружинный динамометр.

На рис. 1 приведена схема вращения цилиндров ветродвигателя в противоположных направлениях.

Опыты проводились над ветродвигателем с двумя вращающимися цилиндрическими лопастями с шероховатой поверхностью диаметром $100 \mathrm{~mm}$ и длиной $200 \mathrm{~mm}$. При

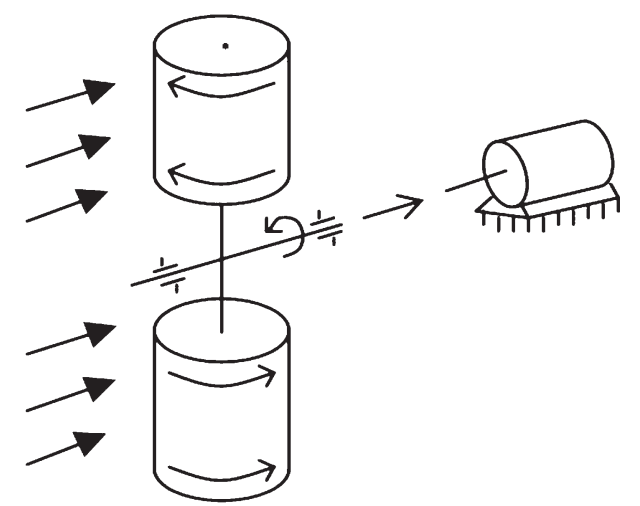

Рис. 1. Схема вращения цилиндров ветродвигателя.

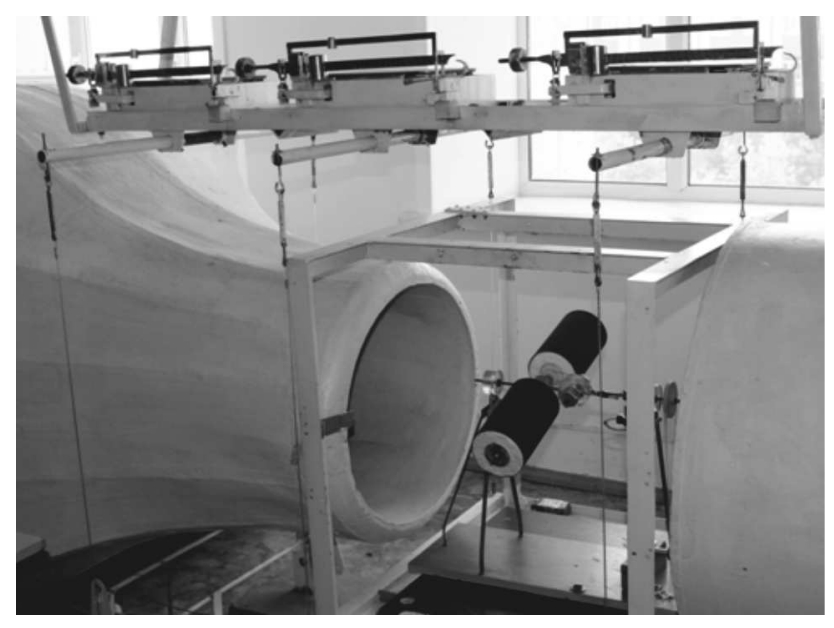

Рис. 2. Модель ветродвигателя с двумя вращающимися элементами, располагаемая в рабочей части аэродинамической трубы.

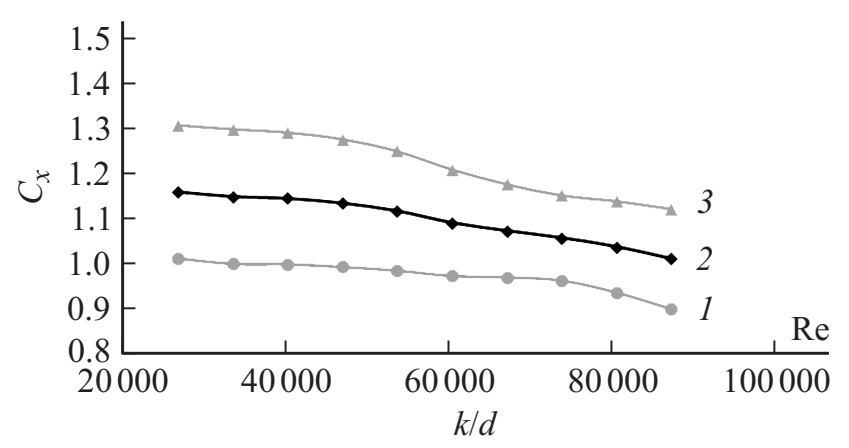

Рис. 3. График зависимостей коэффициентов лобового сопротивления ветродвигателя от изменения чисел Рейнольдса. $k / d: 1-0.005,2-0.01,3-0.02$.

этом скорость набегающего потока и частота вращения цилиндров оставались неизменными.

На рис. 2 показана модель ветродвигателя с вращающимися элементами с шероховатой поверхностью, расположенными в рабочей части аэродинамической трубы.

Во время исследования относительная шероховатость изменялась в диапазоне $0.002-0.02$; безразмерный критерий скорости и режима потока менялся в пределах $20000-105000$.

Формула для определения относительной шероховатости

$$
\bar{k}=\frac{k}{d}
$$

где $k$ - средняя высота выступов шероховатости поверхности цилиндров, $d$ - диаметр цилиндра.

Распределение шероховатости по поверхности цилиндра равномерное. Поверхностная плотность зернистости шероховатой среды $100-120$ grains $/ \mathrm{cm}^{2}$.

\section{Результаты исследования}

По полученным результатам исследований аэродинамических сил были рассчитаны коэффициенты лобового сопротивления, коэффициенты силы тяги и построены графики зависимостей.

На рис. 3 приведен график зависимости коэффициентов лобового сопротивления ветродвигателя от числа Рейнольдса при значениях относительной шероховатости $0.005-0.02$.

Из рис. 3 видно, что с увеличением числа Рейнольдса уменьшается коэффициент лобового сопротивления при всех указанных значениях относительной шероховатости. При этом разность изменения коэффициента лобового сопротивления незначительна. Это связано с тем, что при большой скорости воздушного потока завихренная область за цилиндром из-за напорной энергии потока отделяется от стенки вращающихся цилиндров. В этом случае возрастание лобового сопротивления к обтекающему потоку снижается, так как коэффициент 


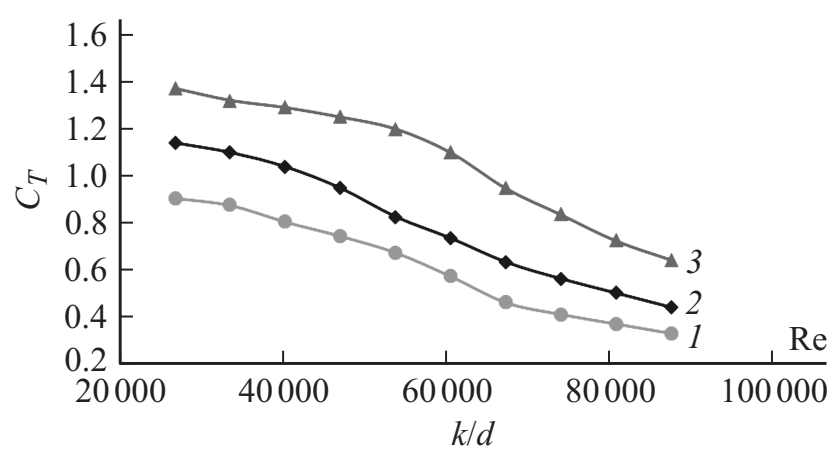

Pис. 4. График зависимостей коэффициентов силы тяги ветродвигателя от изменения чисел Рейнольдса. $k / d: 1-0.005$, $2-0.01,3-0.02$.

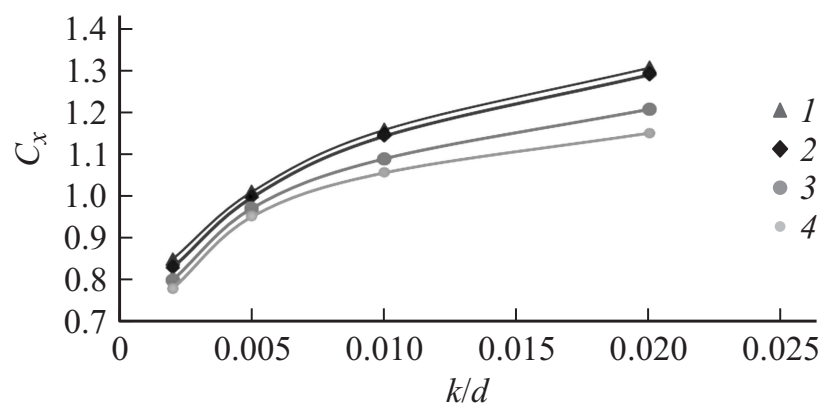

Рис. 5. График зависимости коэффициентов лобового сопротивления ветродвигателя от изменения относительной шероховатости. $U, \mathrm{~m} / \mathrm{s}: 1-4,2-6,3-8,4-10$.

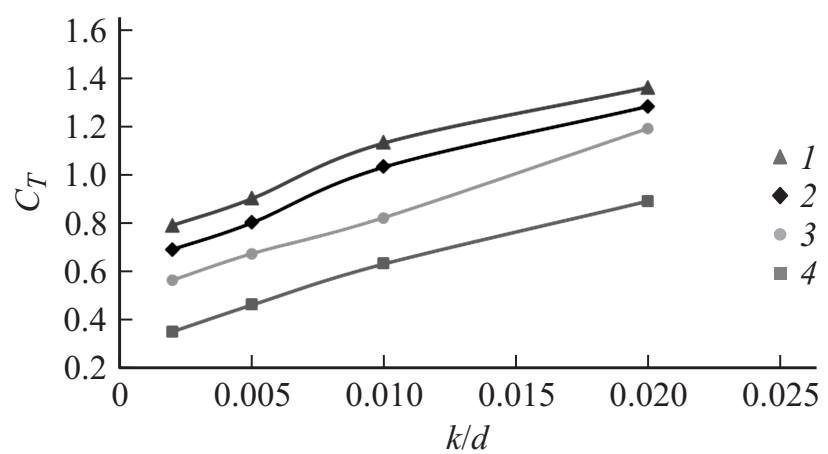

Рис. 6. График зависимостей коэффициентов силы тяги ветродвигателя от относительной шероховатости. $U, \mathrm{~m} / \mathrm{s}: 1-4$, $2-6,3-8,4-10$.

прямо пропорционален лобовой силе, но обратно пропорционален квадрату скорости ветра.

На рис. 4 показана зависимость коэффициента силы тяги ветродвигателя с лопастями в виде вращающихся цилиндров с шероховатой поверхностью от чисел Рейнольдса. Видно, что коэффициент силы тяги ветродвигателя с цилиндрическими лопастями с шероховатой поверхностю уменьшается с увеличением числа Рейнолдьса.

В следующих исследованиях проводилось определение степени влияния изменения относительной ше- роховатости на коэффициент лобового сопротивления и коэффициент силы тяги. Результаты приведены на рис. 5 и 6.

Видно, что при возрастании относительной шероховатости увеличиваются коэффициент силы тяги и коэффициент лобового сопротивления. Приведенные зависимости на рисунках получены во время изменения скоростей потока от 4 до $10 \mathrm{~m} / \mathrm{s}$.

Причина заключается в следующем: при обтекании вращающихся цилиндров с шероховатой поверхностью воздушным потоком на его поверхности образуется пограничный слой, который с увеличением относительной шероховатости будет расширяться.

Цилиндры при вращении увлекают за собой частицы воздуха, находящиеся вблизи их поверхности. Эти частицы будут двигаться по поверхности цилиндра по направлению вращения цилиндра, создавая вращательный воздушный поток.

При обтекании вращающегося цилиндра воздушным потоком частицы воздуха набегающего потока, обтекая цилиндр, изменяют свою траекторию движения по направлению вращения цилиндра. Увлекание частиц набегающего потока вращательным потоком и сгиб линии набегающего потока зависят от типа поверхности и скорости вращения. Цилиндр с шероховатой поверхностью при вращении более увлекает набегающий поток, чем цилиндр с гладкой поверхностью.

\section{Заключение}

Как показали исследования, сила лобового сопротивления, сила тяги и соответсвенно их коэффициенты увеличиваются с возрастанием относительной шероховатости. Это обясняется тем, что шероховатая поверхность вращающегося цилиндра охватывает по сравнению с гладкой поверхностью бо́льшую часть набегающего потока, формируя широкие пограничные слои. С возрастанием относительной шероховатости от $\bar{k}=0.002$ до $\bar{k}=0.02$ коэффициент лобового сопротивления увеличивается на 1.5 раза, а коэффициент силы тяги в 3 раза.

Установлено, что шероховатая поверхность положительно влияет на улучшение аэродинамических характеристик двухлопастного ветродвигателя с цилиндрическими роторами. Увеличение относительной шероховатости поверхности цилиндрической лопасти позволяет повысить работоспособность ветродвигателя.

\section{Список литературы}

[1] Республика Казахстан. Закон РК. О поддержке использования возобновляемых источников энергии: принят 4 июля 2009 г., № 165-IV3PK.

[2] Бычков Н.М. // Теплофизика и аэромеханика. 2005. Т. 12. № 1. C. 159-175. 
[3] Бычков Н.М., Коваленко В.М. // Изв. СО АН СССР. Сер. техн. наук. 1980. № 8. Вып. 2. С. 125-135.

[4] Кусаиынов К., Танашева Н.К., Тургунов М.М., Дюсембаева А.Н., Алибекова А.Р. // Вест. Томского государственного ун-та. Математика и механика. 2014. № 4(30). С. 82-87.

[5] Кусаиынов К., Шрагер Э.Р., Танашева Н.К., Тургунов М. // Вест. Карагандинского ун-та. Сер. Физика. 2014. № 2(76). C. $75-79$.

[6] Бычков Н.М., Коваленко В.М. // Изв. СО АН СССР. Сер. техн. наук. 1981. № 8. Вып. 2. С. 32-39.

[7] Кусаинов К., Танашева Н.К., Тургунов М.М., Алибекова А.Р. // ЖТФ. 2015. Т. 85. Вып. 5. С. 23-26. 